\title{
The Brady Rule May Hurt the Innocent
}

N. Garoupa

Texas A\&M University School of Law, ngaroup@gmu.edu

Matteo Rizzolli

Follow this and additional works at: https://scholarship.law.tamu.edu/facscholar

Part of the Criminal Law Commons, and the Law Enforcement and Corrections Commons

\section{Recommended Citation}

N. Garoupa \& Matteo Rizzolli, The Brady Rule May Hurt the Innocent, 13 Amer. L. \& Econ. Rev. 168 (2011). Available at: https://scholarship.law.tamu.edu/facscholar/620

This Article is brought to you for free and open access by Texas A\&M Law Scholarship. It has been accepted for inclusion in Faculty Scholarship by an authorized administrator of Texas A\&M Law Scholarship. For more information, please contact aretteen@law.tamu.edu. 


\section{The Brady Rule May Hurt the Innocent}

Nuno Garoupa, University of Illinois College of Law, and

Matteo Rizzolli, Free University of Bozen-Bolzano

Send correspondence to: Nuno Garoupa, University of Illinois College of Law, 504 East Pennsylvania Avenue, Champaign, IL 61820, USA; Tel: 217-333-5202; Fax: 217-244-1478; E-mail: ngaroupa@law.uiuc.edu.

Mandatory disclosure of evidence (the so-called Brady rule) is considered to be among the most important bulwarks against prosecutorial misconduct. While protecting the generality of defendants in the criminal process, we show that under certain reasonable assumptions this procedural mechanism may hurt innocent defendants by inducing prosecutors to adjust their behavior to their detriment. The main rationale for our thesis is that, if forced to reveal exculpatory information, the prosecutor might not look for that information in the first place, and in turn this could harm the innocent under certain reasonable conditions. We extensively discuss our results in the context of the economic literature on criminal procedure. (JEL K14, K41, K42)

\section{Introduction}

In modern legal systems, criminal procedure is usually biased toward the interests of defendants (Hylton and Khanna, 2007). The mechanisms of criminal procedure are multiple and encompass, inter alia, the determination of factual evidence, the interpretation of substantive law, the role of the judge vis-à-vis the prosecutor and the defendant, and the possibility of appealing to the highest court. These mechanisms enrich a menu of tools that each legal system can deploy in order to tilt to different degrees the procedure toward the interests of defendants. In this paper, we focus on mandatory disclosure of exculpatory evidence (the so-called Brady rule). We argue that the Brady rule may have a counterintuitive effect on the prosecutor's choice of enforcement technology. The search for more accurate evidence could be 
undermined by the Brady rule because the prosecutor loses the exclusive property rights over the information. ${ }^{1}$ Such a strategic adjustment may have important consequences for the quality of convictions, welfare of innocents, and overall criminal deterrence.

In order to qualify our claim, consider the following examples of the adverse consequences that may arise from the application of the Brady rule.

Example 1: Exculpatory evidence leaked from within the prosecutorial office. Suppose the defendant claims that he was not at the crime's scene when it was committed. Unknown to the defendant, the crime has been recorded by surveillance cameras from the bank next door. The prosecutor, who believes he is guilty, can ask the bank for the recorded tapes. The prosecutor has to assess the benefits of using new (perhaps incriminating) evidence against the costs of jeopardizing the odds of prosecution (if the evidence is exculpatory and has to be disclosed). Of course, if the prosecutor were not bound to disclose exculpatory evidence, she would not hesitate to look at the recorded tapes in the hope of finding incriminating proofs. Once this evidence exists, there is a possibility that the defendant gains access to it because somebody in the prosecutorial office, moved by moral regret, personal rivalry, or economic returns, leaks it to the defendant's lawyers.

Example 2: Exculpatory evidence is produced by the defendant's attorney observing the prosecutor's behavior. Suppose we deal with a serious financial crime. The evidence collected thus far may be enough for the prosecutor to win the case. Moreover, she could have access to some financial statements in foreign bank accounts that would provide evidence of further crimes. There is a risk nevertheless; the financial statements might show no other crime and instead provide exculpatory evidence. Because of the Brady rule, the prosecutor might abstain from asking foreign banking institutions to produce such financial statements. At the same time, an innocent defendant would want the prosecutor to pursue this line of investigation for further evidence. In fact, although the prosecutor may withhold any exculpatory evidence that could emerge, the defendant could benefit, for instance,

1. In that sense, our result follows the information literature where mandatory disclosure may lead to too little investment in the acquisition of information in the first place (Shavell, 1994; Polinsky and Shavell, 2006). 
by simply observing the prosecutor's search strategy and learning where to look for evidence to his own advantage.

Example 3: Exculpatory evidence is produced by the media pressing the prosecutor. Suppose now a prosecutor is investigating an important politician for corruption against which the evidence seems strong. There is the possibility that certain confidential documents could provide the ultimate evidence to convict the politician. However, those same confidential documents might instead provide exculpatory evidence. Under the Brady rule, the prosecutor has no strong incentive to search for those confidential documents. Without the Brady rule, the prosecutor might be willing to take the risk. If she finds some exculpatory evidence, the prosecutor may not disclose it voluntarily as she might be ultimately convinced of the politician's corruption or simply she might only care about obtaining the conviction. However, the press might inevitably report on the actions taken by the prosecutor or pressure her to explain any inconsistency in her prosecutorial strategies and therefore leak the existence of such evidence and thus help the case of the innocent politician accused of corruption. Notice that, although the evidence is brought upon by the press, the prosecutor has produced it in the first place.

The examples encompass multiple types of crimes, varieties of evidence collected, different motivations of the prosecutor, and several methods by which the exculpatory evidence may nevertheless reach the defendant even without mandatory disclosure. However, in all these examples, the Brady rule discourages investigative activities that benefit defendants. The prosecutor who feels strongly about the case may give up searching for further evidence, fully discounting the occurrence that more investigation may end up jeopardizing her case by uncovering exculpatory evidence. Conversely, without mandatory disclosure the prosecutor discounts this occurrence only by a certain probability. In fact, evidence may be collected and, if exculpatory, be withheld. However, with some probability, it could be leaked to the defendant.

Our main insight is that if the prosecutor is induced to investigate more in the absence of the Brady rule, then exculpatory information may leak and benefit the innocent. More generally, one could say that prosecutors often have some exculpatory evidence anyway. Without the Brady rule, all exculpatory evidence can be hidden (including what they have from the beginning of the investigation). For the Brady rule to disadvantage innocent people, the 
loss of all exculpatory evidence has to be less important than the benefit of new exculpatory evidence that can be leaked. There are many reasons to think this is a reasonable assumption under some conditions.

Withholding exculpatory evidence usually requires a conspiracy of the prosecutor with third parties (enforcement agencies, private parties, etc.). The more extensive the conspiracy is, the more likely leaking is to take place. Other procedural safeguards, such as the defendant's right to call witnesses who could be third parties in the investigation, help undermine a strong conspiracy. At the same time, actions taken by the prosecutor are observed by the defendant's lawyer in many occasions and they could potentially reveal the extent to which she is hiding evidence. Finally, many cases attract the interest of other parties such as the press that inevitably disadvantages the prosecutor in eliminating exculpatory evidence.

The original case that set the Brady rule is an example of how exculpatory evidence can leak despite the effort by the prosecutor to hide it. ${ }^{2}$ What this example also shows is that, in the absence of mandatory disclosure, exculpatory evidence may take time to emerge and, in particular, may well emerge only after a defendant has been tried, at which time presumably it can no longer significantly help him. Therefore, our insight should apply to a particular subset of cases for which we think revelation of withheld evidence by the prosecutor that directly benefits the defendant is likely.

We do not claim that the Brady rule always hurts the innocent. Quite the opposite; we show that, in some cases, the Brady rule helps all defendants. However, we argue that, under certain specific conditions, the mandatory disclosure of evidence hurts innocent defendants and helps guilty defendants. The novelty of our paper is to provide conditions under which the Brady rule is detrimental to innocent defendants, a point so far neglected in the literature. Let us be clear about the fact that our argument does not offer support of the abolishment of the Brady rule. In fact, since we identify specific circumstances under which the Brady rule is detrimental,

2. Brady v. Maryland (373 U.S. 83, 1963). The case was about a murder trial in which the petitioner admitted participating in the crime but claimed that his accomplice did the actual killing. The petitioner was convicted, and his appeal was denied. It was later discovered that the prosecutor in the case had withheld a written statement by the petitioner's accomplice in which the accomplice confessed to doing the actual killing - but only years after the trial. 
the main implication of our model is that the Brady rule should be more carefully applied when those specific circumstances arise, and therefore it is important to develop legal policies to decrease the likelihood that those specific circumstances arise.

In the model, a defendant is either innocent or guilty. Not knowing the defendant's type, and given all the available evidence to date, the prosecutor chooses either to (i) drop the case; (ii) prosecute the case passively (i.e., proceed with only the evidence available to date); or (iii) prosecute the case actively (i.e., gather additional evidence and proceed). If the prosecutor actively prosecutes the case, she receives additional evidence that is either incriminating or exculpatory. If the prosecutor passively prosecutes the case, the defendant is convicted with some probability between zero and one. If she actively prosecutes the case and receives additional incriminating evidence, she shares it with the court and the defendant is convicted with probability one. If she actively prosecutes the case and receives additional exculpatory evidence, the outcome depends on whether or not the Brady rule is in effect. If the Brady rule is in effect, the additional exculpatory evidence is shared with the court and the defendant is acquitted with probability one. If it is not in effect, the prosecutor hides the additional exculpatory evidence; however, it is assumed that the additional exculpatory evidence may nonetheless leak to the court once it has been produced. Thus, the probability that the defendant is convicted is lower than in the absence of producing such evidence.

We assume that the prosecutor chooses her prosecutorial strategy to maximize its payoff. She incurs a cost for prosecuting the case and an additional cost for prosecuting the case actively. She derives a benefit from a conviction, the benefit being higher when the defendant is guilty and lower when the defendant is innocent. Under certain conditions, the Brady rule can induce the prosecutor to switch from prosecuting actively to prosecuting passively, and thereby it may increase the probability that an innocent defendant is convicted. Intuitively, without a rule of mandatory disclosure, the prosecutor may want to produce additional evidence even if it already has a pretty strong case against the defendant because if the additional evidence turns out to be incriminating, she can use it to bolster the case against the defendant even further and if it turns out to be exculpatory, she has some chance of preventing it from leaking, in which case it will not weaken her case. However, with a rule of mandatory disclosure, if she already has a pretty strong case against the defendant, she may prefer not to produce additional evidence because 
now, if it turns out to be exculpatory, it must be disclosed and this will weaken her case. Thus, without the Brady rule, the additional evidence may be produced, and once it is produced, it may leak, in which case the innocent can benefit from it. But with a rule of mandatory disclosure, the evidence will not be produced, in which case it has no chance of helping the innocent. In these circumstances, the Brady rule can increase the probability that an innocent defendant is convicted.

In the first section of the present work, we review the literature on the behavior of prosecutors. In the following section, we discuss some of the more important pro-defendant mechanisms and we focus on the kind of errors they generate. In the fourth section, we lay down our model that combines self-interested prosecutors with mandatory disclosure of exculpatory evidence. Our main goal is to show, in a simple model, that the procedural safeguard that is supposed to be in place in order to protect defendants may end up hurting the subset of accused that are in fact innocent. In the fifth section, we assess some possible limitations of the model and legal policy implications. Section 6 concludes the paper.

\section{What the Prosecutor Is up to}

Early works in law and economics assumed that the judiciary pursues the general interest of society. In his account of courts, Landes (1971) modeled prosecutors as individuals who maximize the expected number of convictions weighted by the length of conviction. This objective function, Landes then argued, coincides with the social optimum as long as one assumes that sentences correspond to the expected prices society charges for the related crimes. Most of the models in the stream of literature on optimal law enforcement ${ }^{3}$ are built on the assumption that prosecutors, together with the judiciary, behave benevolently; that is to say, they second a social welfare-maximizing goal-whether this is optimal deterrence (Becker, 1968), absolute deterrence (Posner, 1985; on the distinction between Becker and Posner, see Hylton, 2005), retribution (Kahan, 1998), or victim compensation (Fletcher, 1995) — in enforcing criminal law, therefore making appropriate use of criminal procedure.

3. For comprehensive surveys of the literature, see Garoupa (1997) and Polinsky and Shavell (2000). 
On the other hand, legal scholars have long pointed out the discrepancies between the idealistic stereotype of the benevolent judiciary and the reality of trials and prosecution. To begin with, prosecutors have tremendous discretion over the reputation, liberty, and life of individuals (Jackson, 1940). Obviously, discretion need not necessarily be a problem in itself; Easterbrook (1983), for instance, assumes that prosecutors use their discretion to optimally screen cases that maximize deterrence given their budget constraints. However, this latter view might be naive or quite unrealistic, as prosecutors' discretion is certainly open and often prone to abuses (Wright, 2005; Garoupa and Stephen, 2008). For example, Schulhofer (1988) argues that, as self-interested agents, prosecutors' decisions naturally diverge from those that would be made in the interest of the public. Prosecutors may pursue other goals such as salary and further career advances (see, among others, Christensen, 1981; Glaeser, Kessler, and Morrison Piehl, 2000; Boylan, 2005; Long and Boylan, 2005; Garoupa, 2009) as well as reelection (Gordon and Huber, 2002). These other goals are often parameterized on the record of convictions (Meares, 1995), which is a very imperfect measure of the performance of the justice system. Furthermore, other factors may misalign the incentives of the prosecutor such as risk aversion (Albonetti, 1987) or simply the different weight they attribute to the social costs of false positives (Hylton and Khanna, 2007). Miceli (1990) notes how the same prosecutorial goals set forth by William Landes in his seminal article do not match with societal goals once one includes the possibility of erroneous convictions. ${ }^{4}$

In fact, the persistent and systematic misalignment of prosecutorial incentives vis-à-vis societal goals has lead Hylton and Khanna (2007) to formulate a public choice theory of criminal procedure that justifies pro-defendant safeguards as necessary second-best constraints to impede prosecutorial agency problems. We discuss some of these safeguards in the following section.

\section{Mandatory Disclosure in Criminal Procedure}

Criminal procedure supports courts' efforts to sort out factually innocent from truly guilty defendants. Given the risk that some innocents may end up

4. For a model that includes prosecutorial concern for false positives, see Baker and Mezzetti (2001) and also Rasmusen, Manu, and Mark (2009). 
convicted and the fact that not all guilty individuals are necessarily detected and brought to court as defendants (and even if they are, their responsibilities may not be proven in court), criminal procedure struggles to achieve two somewhat conflicting goals: on the one hand, the achievement of greater accuracy in adjudication (Kaplow, 1994) in absolute terms and, on the other hand, the struggle to wrongfully convict as few innocents as possible. The presumption of innocence, which is a cornerstone of all procedures of modern democracies ${ }^{5}$ both in common law ${ }^{6}$ and in civil law countries, ${ }^{7}$ makes the prosecutor bear the burden of proving the culpability of the defendant. In statistical terms, the innocence of the defendant is the null hypothesis the court is presented with and that the prosecutor tries to reject. The court bases its decision upon the evidence presented by both parties and expresses a verdict of guilty/not guilty. There thus could be false positives or wrongful convictions of innocents and false negatives or wrongful acquittals of guilty individuals. Achieving greater accuracy implies the reduction of both types of errors, while not convicting innocents means decreasing only false positives. These two goals are partly conflicting. There is no doubt, however, that most modern legal systems seem to all have the same strong concern with respect to the possible wrongful conviction of an innocent prevailing over the apprehension of a guilty that might in the end escape a due conviction. In order for the first concern to prevail, the criminal procedure can be tilted toward the interests of the defendant in a variety of ways. These encompass, among others, the high level of evidence necessary to

5. Although in diverse guises, it is present in the Universal Declaration of Human Rights (Article 11) and in the Convention for the Protection of Human Rights and Fundamental Freedoms of the Council of Europe (Article 6.2).

6. It is a well-established principle of countries of common law tradition such as the United States (see Coffin v. United States, 156 U.S. 432 (1895)) or Canada (see Section 11(d) of the Canadian Charter of Rights and Freedoms).

7. There is a tendency to consider the presumption of innocence as a feature that best fits the adversarial system of common law countries rather than the inquisitorial system of civil law countries (O'Reilly, 1994). However, this is not necessarily the case; see for instance, Ingraham (1996). The presumption of innocence is, for instance, clearly remarked in the French Declaration of the Rights of Man and of the Citizen (Article 9) that has constitutional value and in Article 27 of the Italian constitution. 
convict, ${ }^{8}$ the set of rights which the defendant is entitled to (such as the right to silence) or asymmetric appeal rights that impede the prosecutor to appeal an acquittal at trial, and finally the set of duties imposed on the prosecutor such as mandatory disclosure of evidence.

In general terms, mandatory disclosure forces the parties to reveal information in their possession upon the request of the counterpart. In criminal procedure, mandatory disclosure is thus a pro-defendant safeguard in so far as it supports the emergence of exculpatory evidence. In the United States, mandatory disclosure descends from the due-process requirements embedded in the Fifth Amendment to the Constitution. After Brady v. Maryland, 373 U.S. 83, 84 (1963), which made the disclosure of exculpatory evidence in favor of the defendant compulsory for the prosecutor, the failure of prosecutors to fully disclose information has led to the upholding of countless cases (Gershman, 2006) and the so-called Brady rule has been codified in both prosecutorial guidelines and incorporated into an explicit ethical duty upon government attorneys (American Bar Association, 1993). More binding and enforceable rules to constrain prosecutorial behavior have in the meanwhile been advocated (Kurcias, 2000; Green, 2003). The intent of

8. Different burdens of proof imply different thresholds of rejections of the null hypothesis. It is safe to argue that the higher the standard required - all else being equalthe more difficult it is to achieve a conviction and hence the lower the number of innocents convicted (false positives) and the higher the number of guilty individuals acquitted (false negatives). In civil cases (where the standard of preponderance of evidence applies), the plaintiff must show that her claims are "more likely than not" true. Conversely, in order to obtain a criminal conviction, the prosecutor must convince the judge beyond any reasonable doubt. The law and economics literature on the standard of proof is extensive and takes different routes. One first venue is the determination of the optimal standard of proof. Some authors model the standard that minimizes the social costs of judicial errors with exogenous false-positive and false-negative costs (Miceli, 1991; Yilankaya, 2002). Others derive the optimal standard from litigation expenditures (Hay and Spier, 1997), litigation expenditures vis-à-vis error costs (Rubinfeld and Sappington, 1987), the fact-finding technology (Sanchirico, 1997), and the optimal exertion of care by parties (Demougin and Fluet, 2006). Another stream of literature addresses parties' incentives to disclose evidence; see Milgrom and Roberts (1986) discussing sufficient conditions for full revelation by parties and optimal strategies for decision makers; Shavell (1989) discussing optimal sanctions to trigger revelation of evidence to courts; Shin (1998) arguing the superiority of the adversarial systems as a mechanism of evidence revelation by the parties; Cooter and Emons $(2003,2004)$ showing that perjury is an imperfect truth-revealing mechanism used to force the disclosure of evidence and suggesting more efficient mechanisms based on strict liability and bond-posting of witnesses. 
Brady was to compel prosecutors to their constitutional mandate of guaranteeing the defendant a due process. ${ }^{9}$

Law and economics scholars have shown how mandatory disclosure smoothens the discovery process, increments the rate of settlements, and reduces transaction costs (for a general overview, see Cooter and Rubinfeld, 1994) and agency costs in particular (Mahoney, 1995). On the other hand, it has been shown that mandatory disclosure may have an ambiguous effect on convictions if not coupled with the right to silence. ${ }^{10}$ This is because if, on the one hand, mandatory disclosure tends to reduce convictions directly as more exculpatory evidence is produced, on the other hand, it tends to increase convictions indirectly by worsening the jury's adverse inference from the defense's silence. Under mandatory disclosure, assuming that the defendant has better information on the case, the jury may be less inclined to believe that the defendant remains silent because she does not know the evidence and more likely to believe that the defendant keeps her mouth shut because the evidence is incriminating. ${ }^{11}$

9. Although the obligation to disclose has constrained prosecutors' discretion, it has arguably failed to align their incentives with the societal pursuit of fair trials if it is true that prosecutorial suppression of evidence has accounted for 16-19\% of reversible errors of death-penalty sentences between 1973 and 1995, according to Gelman et al. (2004), and that, according to Bedau and Radelet (1987), one in 10 of 350 wrongful death-sentence convictions held between 1900 and 1985 were the result of prosecutorial suppression of evidence.

10. The right to remain silent is another cornerstone of criminal procedure in common law countries. Noticeably, the right to silence was withdrawn in Northern Ireland in 1988 and England in 1994 in order to facilitate the conviction of suspected terrorists (Mialon, 2005). In the United States, it derives from the Fifth Amendment. After Griffin v. California, 380 U.S. 609 (1965), the right to silence, on the one hand, recognizes the right of the defendant to not self-incriminate (witnesses may instead be held liable if they refuse testimony) and, on the other hand, it prevents the jury from inferring any conclusion from the defendant's silence. See Seidmann and Stein (2000) and Seidmann (2005).

11. Seidmann and Stein (2000) and Seidmann (2005) argue that, absent of the right to silence, the guilty mimics the innocent and by doing so he pools with them, thus undermining the credibility of innocents that make exculpatory statements. This, in turn, increases the probability that innocents are convicted wrongfully. Mialon (2005) furthers the case for the right to silence by noting that, when evidence pertaining to culpability is inaccurate or unknown to the defendant, she may prefer to stay silent either because the evidence might indicate that she is guilty or because she might not know the evidence she is charged with. In either case, the innocent defendant might be wrongfully convicted if the adverse inference from silence is not prevented but correctly acquitted if the right to silence is in place. 
To conclude, the Brady rule is a distinctive feature of the American criminal procedure. It is an eminent aspect of procedure as it is believed to constitute an important procedural safeguard for errors against innocent defendants. Scholars have been so far divided between those emphasizing the "false-negative" downside of this pro-defendant feature ${ }^{12}$ and those celebrating its merits in terms of successful restraint on prosecutorial abuses (Hylton and Khanna, 2007). Neither side of the argument disputes the fact that mandatory disclosure in criminal procedure works in the interests of defendants. Our paper questions this point. We argue that this pro-defendant mechanism, while helping defendants in general, may end up hurting the innocents accused. In the following section, we show that, under certain conditions, the innocent defendant is not well served by the Brady rule.

\section{The Model}

Suppose defendants facing the court are guilty with probability $q$ and not guilty with probability $1-q$, exogenous in the model (see the following section for further discussion). The prosecutor cannot distinguish individuals in terms of their culpability and thus, even if the prosecutor dislikes prosecuting and convicting innocents, she cannot perfectly rule out judgment errors.

\subsection{Strategy Set for the Prosecutor}

A prosecutor can choose one of three prosecutorial strategies:

(1) Drop: the prosecutor decides to discontinue the case and drop all charges;

(2) Passive: the prosecutor makes no further investigation after the evidence is gathered by the police but pursues the case seeking a conviction;

(3) Active: the prosecutor operates further investigation that might or might not actually reveal the true behavior of the accused before continuing with the case.

12. That is to say the fact that it may help guilty individuals to escape conviction. See Atkins and Rubin (2003) and Cassell and Fowles (1998). 
If no further investigation is pursued, a guilty individual is convicted with probability $p_{\mathrm{g}}$ and an innocent is convicted with probability $p_{\mathrm{i}}\left(<p_{\mathrm{g}}\right){ }^{13}$

However, if the prosecutor decides to be active more evidence can be obtained. We consider two possibilities: (i) incriminating evidence and (ii) exculpatory evidence. Notice that the results of our model are robust to the inclusion of a third possibility, a mix of incriminating and exculpatory evidence, or no evidence. ${ }^{14}$ For sake of exposition, we consider a simple model with (i) and (ii) only. Table 1 summarizes the probabilities that each type of evidence is obtained after further investigation.

The only assumption is that $x<y$. This simply means that, by searching for further evidence, the prosecutor is more likely to obtain exculpatory evidence when the defendant is innocent and more likely to obtain incriminatory evidence when the defendant is guilty. Notice that this restriction is mild as it does not imply that accuracy necessarily improves with further investigation since $x>0$ and $y<1$.

Under mandatory disclosure, the consequences of gathering more information are the following:

(1) $\left(\mathrm{A}_{\mathrm{MD}}\right)$ Incriminatory evidence: this secures a conviction with probability one. ${ }^{15}$

(2) $\left(\mathrm{B}_{\mathrm{MD}}\right)$ Exculpatory evidence: this fully undermines prosecution and therefore the case is dropped.

Table 1. Probabilities of Incriminatory Evidence Conditional on Type

\begin{tabular}{lcc}
\hline & Incriminating & Exculpatory \\
\hline Guilty $(q)$ & $y$ & $1-y$ \\
Innocent $(1-q)$ & $x$ & $1-x$ \\
\hline
\end{tabular}

13. These probabilities are determined by the evidence already gathered by the enforcement agencies and shared with the defendant. Moreover, further evidence can be introduced later by other parties, including the defendant. In this context, a rule of mandatory disclosure does not change these probabilities.

14. By obtaining a mix of incriminatory, exculpatory, mere circumstantial, or even no further evidence, we should assume that the probabilities of conviction are unaltered, hence $p_{\mathrm{g}}$ and $p_{\mathrm{i}}$ for the guilty and for the innocent, respectively (the decision to gather more information has neither helped nor hurt the prosecutor).

15. This is a mere normalization. In fact, all the results of the paper would still be valid with a probability of conviction less than one. 
Table 2. Prosecutorial Strategies Conditional on Type and Disclosure Regime

\begin{tabular}{lcccc}
\hline & Drop & Passive & $\begin{array}{c}\text { Active and } \\
\text { incriminatory }\end{array}$ & $\begin{array}{c}\text { Active and } \\
\text { exculpatory }\end{array}$ \\
\hline Guilty mandatory & 0 & $p_{\mathrm{g}}$ & 1 & 0 \\
Guilty voluntary & 0 & $p_{\mathrm{g}}$ & 1 & $r_{\mathrm{g}}$ \\
Innocent mandatory & 0 & $p_{\mathrm{i}}$ & 1 & 0 \\
Innocent voluntary & 0 & $p_{\mathrm{i}}$ & 1 & $r_{\mathrm{i}}$ \\
\hline
\end{tabular}

Under voluntary disclosure, the consequences of gathering more information are the following:

(1) $\left(\mathrm{A}_{\mathrm{VD}}\right)$ Incriminatory evidence: this still secures a conviction with probability one since the evidence will be voluntary disclosed.

(2) $\left(\mathrm{B}_{\mathrm{VD}}\right)$ Exculpatory evidence: now this evidence is willfully not disclosed any longer. However, it still affects the probabilities of conviction because it might be leaked or it might affect the behavior of the enforcement authorities who had access to the information, thus revealing the existence of such evidence. We assume that the probabilities of conviction are altered to $r_{\mathrm{g}}$ and $r_{\mathrm{i}}$ for the guilty and for the innocent, respectively; they are higher than zero (under mandatory disclosure they are zero) but less than $p_{\mathrm{g}}$ and $p_{\mathrm{i}}$, respectively.

The process of further investigation and information gathering has two possible outcomes. It may help the prosecutor by collecting incriminatory evidence, or it may hurt the prosecutor by collecting exculpatory evidence.

The probabilities of conviction are summarized in Table 2. A first look at this table could tempt us to conclude that the accused, either guilty or innocent, is necessarily better off under the Brady rule since the probability of conviction decreases when exculpatory evidence is gathered and remains constant in all other cases. However, the point of our paper is that such a naive conclusion neglects the incentives provided for the prosecutor to adjust strategies. Such an adjustment of strategies might actually hurt the innocent accused and benefit the guilty since the prosecutor cannot distinguish individual culpability.

\subsection{Prosecutor's Payoffs}

The loss for the prosecutor from an acquittal is zero, whereas the benefit for the prosecutor from winning depends on the nature of the defendant. A 
conviction of a guilty defendant provides a gain normalized to one, whereas a conviction of an innocent defendant provides only $V \leq 1$. A prosecutor who is indifferent to the culpability of the accused and only cares about maximizing convictions has $V=1$. A prosecutor who wishes to convict only the culpable accused should have $V=0 .{ }^{16}$ Notice that the prosecutor cannot perfectly distinguish a culpable from an innocent defendant; she does not know whether the specific defendant belongs to the $q$ or the $1-q$ pool. However, she knows the probability $q$ and therefore she can compute her expected payoffs. ${ }^{17}$

While dropping the case implies no cost for the prosecutor, we assume that the passive strategy comes at a cost $S$, whereas the active strategy comes at a cost $C$. These costs are positively correlated such that $S(C)$ and $S^{\prime}(C)>$ 0 . This is because if it is costly to pursue a certain case, it is also expensive to operate further investigation.

In terms of payoffs, the difference between mandatory and voluntary disclosure of information is that when the process of gathering more information hurts the prosecutor by uncovering exculpatory evidence, it hurts more under mandatory than under voluntary disclosure. As we will see, another way of interpreting this observation is that obtaining further information is relatively more costly under mandatory than under voluntary disclosure because the prosecutor cannot hide new detrimental evidence under the former but she can under the latter.

For the following three subsections, we assume that the prosecutor is risk neutral. Risk aversion is addressed in the last subsection.

16. We use zero as the lower limit for convenience and without loss of generality given the monotonicity of the expected payoffs and first derivatives as we show in the following subsections. We also rule out the case of a sadistic prosecutor that derives utility precisely by punishing the innocents. For such a prosecutor, $V>1$.

17. Indeed if the prosecutor could perfectly discriminate, then she would opt for dropping all cases against innocents, anticipating that the odds of eventually winning the case when the defendant is innocent are low. If this were the case, mandatory disclosure would be pointless because no innocent would risk a wrongful conviction. Conversely, if the prosecutor does not even know the probability $q$, she would simply consider all defendants as presumably guilty and thus extract a payoff $V=1$ from the conviction of each of them. 


\subsection{Mandatory Disclosure and Prosecutor's Behavior}

Under mandatory disclosure, the expected payoffs of the prosecutor are as following:

$$
\left\{\begin{aligned}
E(\pi)_{\mathrm{MD}}^{\mathrm{drop}} & =0 \\
E(\pi)_{\mathrm{MD}}^{\mathrm{passive}} & =q p_{\mathrm{g}}+(1-q) p_{\mathrm{i}} V-S(C), \\
E(\pi)_{\mathrm{MD}}^{\text {active }} & =q y+(1-q) x V-C-S(C) .
\end{aligned}\right.
$$

With the following assumption, we consider only the case where being active generates higher payoffs than being passive.

Assumption 1. $q\left(y-p_{g}\right)+(1-q)\left(x-p_{i}\right) V \geq 0$

Without this assumption the prosecutor would never be active. It should be noticed that dropping this assumption helps our results but makes them less convincing; hence, we opt for the more challenging scenario and impose this restriction. Essentially, it must be the case that, by being active, it is more likely than not that the prosecutor will find incriminating evidence.

The following proposition describes the levels of $C$ that induce the prosecutor to switch behavior among the three possible strategies.

Proposition 1. Assume that $q p_{g}+(1-q) p_{i} V>S\left(q\left(y-p_{g}\right)+(1-q)(x-\right.$ $\left.\left.p_{i}\right) V\right) .{ }^{18}$ The prosecutor chooses (i) drop if $\mathrm{C}>\mathrm{Ca}$; ( ii) passive if $\mathrm{Cb}<\mathrm{C} \leq$ $\mathrm{Ca}$; (iii) active if $\mathrm{C} \leq \mathrm{Cb}$, where $\mathrm{Ca}$ and $\mathrm{Cb}$ are defined in the following way:

$$
\begin{aligned}
S(C a) & =q p_{\mathrm{g}}+(1-q) p_{\mathrm{i}} V, \\
C b & =q\left(y-p_{\mathrm{g}}\right)+(1-q)\left(x-p_{\mathrm{i}}\right) V .
\end{aligned}
$$

Proof. The choice between the active and passive strategy is solved by verifying whether $E(\pi)_{\text {passive }}<E(\pi)_{\text {active }}$. The prosecutor stays active when the costs are less than the critical value $C b$. Note that $C b$ is positive given our Assumption 1. ${ }^{19}$

18. Notice that $q p_{\mathrm{g}}+(1-q) p_{\mathrm{i}} V>S(0)$ is not enough.

19. The intuition is that, if the threshold for costs $C b$ is negative, the prosecutor needs to be subsidized in order to be active since the expected "gain" is actually negative. Therefore, in the absence of subsidies, the prosecutor is always passive. This would make our main result too obvious since when there is mandatory disclosure, the prosecutor is never active, and thus the innocent defendant is always hurt. 
We now turn our attention to the possibility of dropping the case. We first compare $E(\pi)_{\text {drop }}<E(\pi)_{\text {passive }}$. The prosecutor will choose passive over drop if the costs are lower than the critical value $C a$, the implicit definition of which is obtained by equalizing Equation (1) to Equation (2).

$\mathrm{Cb}$ could in principle be higher than $\mathrm{Ca}$. However, this would further simplify the reasoning and lead to trivial and/or uninteresting results ${ }^{20}$ and therefore we have imposed that $C b<C a$. In other words,

$$
q\left(y-p_{\mathrm{g}}\right)+(1-p)\left(x-p_{\mathrm{i}}\right) V<S^{-1}\left(q p_{\mathrm{g}}+(1-q) p_{\mathrm{i}} V\right),
$$

where $S^{-1}(\cdot)$ is the inverted function of $S(C)$. The condition announced at the beginning of the proposition necessarily guarantees that $\mathrm{Cb}<\mathrm{Ca}^{21}$

Finally, we want to show that for all $C \leq C b$, the prosecutor is better off being active rather than dropping the case (it only makes sense for $C b>0$, otherwise the prosecutor is never active). This follows suit from the previous reasoning since we have shown that active is preferred to passive if $C<C b$; passive is preferred to drop if $\mathrm{C}<\mathrm{Ca}$ and by construction $\mathrm{Cb}<\mathrm{Ca}$.

We can graphically represent Proposition 1 along the line of values that the cost of obtaining further evidence $C$ can take, from zero to infinity, in Figure 1.

Cases with high costs of prosecution are dropped. Cases with intermediate costs are prosecuted under a passive strategy, and finally cases with low costs are prosecuted under an active strategy (that might result later in

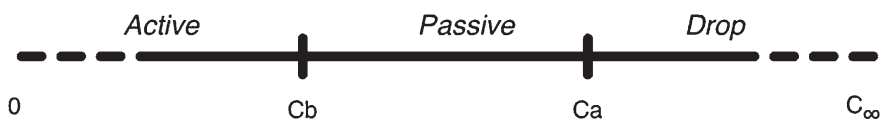

Figure 1. Prosecutorial Strategies Conditional on Costs of Prosecution.

20. If $\mathrm{Cb}>\mathrm{Ca}$, then passive is never an optimal strategy. Let us start with high costs. In that case drop is the best strategy. The first critical value to be encountered as we go down is $C b$. Now the choice is between drop and active. Either could be optimal depending on the critical value, but passive will never emerge as a viable choice. The results of the paper are now in terms of drop and active. We find the setup we have chosen more general and more challenging to our thesis.

21. Since $S(\cdot)$ is increasing in $C$, this means that $q p_{\mathrm{g}}+(1-q) p_{\mathrm{i}} V$ has to be large enough, that is, the expected gain from passive must be large enough to justify not dropping the case. 
conviction, acquittal, or dropping depending on the further evidence gathered). Notice that we are assuming that $C b$ is greater than zero, following Assumption 1. It could be otherwise, in which case the prosecutor would never be active (the technology of further operating evidence hurts the prosecutor on average and so it is never chosen).

Let us assume that the cost $C$ is distributed according to the population of cases, so that each case has a different cost in terms of prosecution and gathering further information, ${ }^{22}$ with a probability density function $g(C)$ and a cumulative density function $G(C)$ with support in $[0, \infty)$. The proportion of cases dropped is $1-G(C a)$, of cases prosecuted under passive is $G(C a)-$ $G(C b)$, and of cases prosecuted under active is $G(C b)$, assuming $C b$ is greater than zero.

\subsection{Prosecutor's Concern with Wrongful Convictions under Mandatory Disclosure}

As argued before, the prosecutor's goals are not aligned with the ones of society, and while some prosecutors may seek to maximize accuracy (convict guilty and acquit innocent defendants), others may simply seek to maximize convictions regardless of actual guilt. In mathematical terms, the prosecutor's concern with defendant's culpability is represented by $V$. From the definitions of $C a$, it is straightforward that it goes up with $V$. As from the definition of $C b$, we can see that it goes up with $V$ if $x>p_{\mathrm{i}}$ and goes down otherwise. Since $x$ is the probability of finding incriminating evidence against an innocent defendant, we suggest that the latter effect is more likely.

Let us start with the case that $C b$ goes down. As the prosecutor cares less about wrongly convicted defendants, we will have fewer cases being dropped, fewer cases being prosecuted under active, and more cases being prosecuted under passive. Because additional information is informative, more opportunistic prosecutors are more reluctant to adopt the active strategy.

Consider now the possibility that $C b$ goes up. The objective function of a prosecutor who cares little of innocents wrongly convicted results in fewer cases being dropped and more cases being prosecuted under active. The

22. Alternatively one can think of the population of prosecutors where some prosecutors are highly ineffective, hence have high costs, whereas others are highly effective, hence have low costs. 
number of cases being prosecuted under passive can go up or down, depending on the density function. Let us differentiate $G(C a)-G(C b)$ with respect to $V$ :

$$
g(C a)(1-q) p_{\mathrm{i}} / S^{\prime}(C a)-g(C b)(1-q)\left(x-p_{\mathrm{i}}\right)
$$

In the limit case that the active strategy is never chosen, because $C b<0$, a more selfish prosecutor results necessarily in more cases being prosecuted under passive and fewer cases being dropped.

\subsection{Voluntary Disclosure}

Remember that, with voluntary disclosure, the prosecutor can withhold exculpatory evidence to some extent, and thus the probabilities of conviction, if such evidence is produced, are $r_{\mathrm{g}}$ (if guilty) and $r_{\mathrm{i}}$ (if innocent) and no longer zero (see Table 2). Notice that the expected payoffs of the prosecutor under drop and passive are unchanged. However, if she is active, we now have a different expected payoff:

$$
E(\pi)_{\mathrm{VD}}^{\text {active }}=q\left[y+(1-y) r_{\mathrm{g}}\right]+(1-q)\left[x+(1-x) r_{\mathrm{i}}\right] V-C-S(C)
$$

Assumption 2. $q\left[y+(1-y) r_{g}-p_{g}\right]+(1-q)\left[x+(1-x) r_{i}-p_{i}\right] V \geq 0$.

This assumption, along the lines of Assumption 1, imposes that the choice of the active strategy generates a net expected gain to the prosecutor also under voluntary disclosure. If this were not the case, she would never choose active. Notice that if Assumption 1 is satisfied, Assumption 2 is also necessarily satisfied.

Proposition 2. Assume that $q p_{g}+(1-q) p_{i} V>S\left(q\left[y+(1-y) r_{g}-p_{g}\right]+\right.$ $\left.(1-q)\left[x+(1-x) r_{i}-p_{i}\right] V\right)$. The prosecutor chooses (i) drop if $\mathrm{C}>\mathrm{Ca}$; (ii) passive if $C c<C \leq C a$; (iii) active if $C \leq C c$, where $C a$ and $C$ c are defined in the following way:

$$
\begin{aligned}
& S(C a)=q p_{\mathrm{g}}+(1-q) p_{\mathrm{i}} V, \\
& C c=q\left[y+(1-y) r_{\mathrm{g}}-p_{\mathrm{g}}\right]+(1-q)\left[x+(1-x) r_{\mathrm{i}}-p_{\mathrm{i}}\right] V .
\end{aligned}
$$

Proof. Similar to Proposition 1.

By direct comparison, we can see that $C c>C b$. The intuition is that the technology for further gathering of information is more favorable to the 


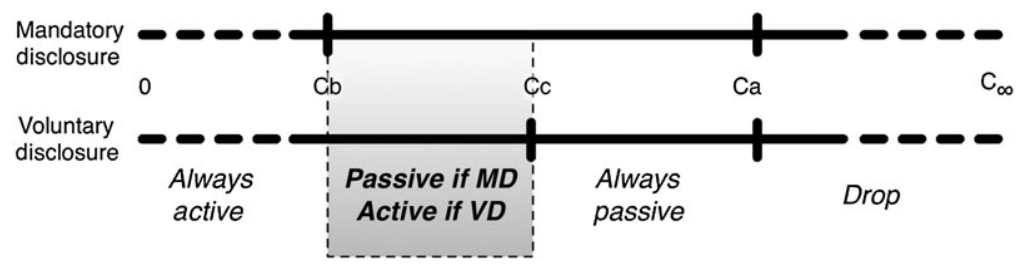

Figure 2. Prosecutorial Strategies Conditional on Costs of Prosecution under Mandatory and Voluntary Disclosure.

prosecutor, on average, under voluntary than under mandatory disclosure. Naturally, this results in active being more likely under voluntary rather than under mandatory disclosure.

We can now represent graphically Propositions 1 and 2 in Figure 2.

Cases with high costs of prosecution are dropped anyway, cases with intermediate high costs are prosecuted under a passive strategy anyway, and cases with low costs are prosecuted under an active strategy anyway. However, cases with intermediate low costs are prosecuted under passive if mandatory disclosure prevails and under active if instead voluntary disclosure is the rule. Notice that we are assuming that $C b$ and $C c$ are greater than zero. If it were otherwise, the cases on the left-hand side of the distribution would progressively disappear. If active is never chosen, there is no difference between mandatory and voluntary disclosure of information since no further gathering of information takes place.

\subsection{Prosecutor's Concern with Wrongful Convictions under Voluntary Disclosure}

We can also investigate how the prosecutor's concern with the culpability of the defendant matters in terms of prosecution under both rules. We have already shown that $C a$ goes up with $V$ and $C b$ depends on $x_{\mathrm{i}}$ being more or less than $p_{\mathrm{i}}$. The value of $C c$ goes up with $V$ if $x\left(1-r_{\mathrm{i}}\right)>p_{\mathrm{i}}-r_{\mathrm{i}}$ and goes down with $V$ otherwise. As before, since $x$ is the probability of finding incriminating evidence against an innocent defendant, we suggest that the latter effect is more likely.

It is clear that there are three possible cases: (i) both $C b$ and $C c$ go down with $V$; (ii) both $C b$ and $C c$ go up with $V$; and (iii) $C b$ goes down but $C c$ goes up with $V$. If they move in opposite directions with $V$, it is straightforward that the number of cases subject to a switch of prosecutorial strategy 
increases as the prosecutor becomes more opportunistic. More opportunistic prosecutors are more reluctant to search for additional evidence if disclosure is mandatory but are less reluctant if disclosure is voluntary.

Consider now the case when both values move in the same direction with $V$. Now, the number of cases being prosecuted that are subject to a switch of prosecutorial strategy in response to disclosure rules can go up or down, depending on the density function. Let us differentiate $G(C c)-G(C b)$ with respect to $V$ :

$$
g(C c)(1-q)\left[x+(1-x) r_{\mathrm{i}}-p_{\mathrm{i}}\right]-g(C b)(1-q)\left[x-p_{\mathrm{i}}\right]
$$

If we assume that the point-wise density is not very different, $g(C c)=$ $g(C b)$, which, for example, is satisfied by the uniform distribution, it is clear that this derivative is positive. If both values go up with $V$, a more selfish prosecutor will increase the number of cases that are exposed to the adjustment of prosecutorial strategy in response to disclosure rules. The opposite happens if both values go down with $V$.

However, let us emphasize that even if $V=0$ (the prosecutor does not benefit from the conviction of innocent defendants), there are still cases in this interval. This is an important observation since it implies that even in presence of a benevolent prosecutor here mandatory disclosure hurts the innocent and helps the guilty (remember in fact that she cannot distinguish guilty from innocent defendants).

\subsection{Welfare of Defendants}

Let us now consider the welfare of the defendants as measured by the probability of conviction. For those cases that are always dropped or always prosecuted under passive, nothing changes; that is, for $C \geq C c$, there is no relevant variation since they do not benefit from further gathering of information. Consider now the situation for those defendants whose cases are always prosecuted under active. They are obviously better off since they are the ones benefiting explicitly from mandatory disclosure as summarized in Table 2 (guilty and innocent alike). The critical group is made by those defendants for which $C$ is between $C b$ and $C c$. With the following proposition, we identify the conditions under which the innocents are worse off and the defendant better off because of the adjustment of prosecutorial strategy. 
Proposition 3. Suppose $C b \leq C<C c$, or equivalently, $q(1-y) r_{g}+(1-$ $q)(1-x) r_{i} V>0$. Innocents are worse off under mandatory disclosure if $x<$ $\left(p_{i}-r_{i}\right) /\left(1-r_{i}\right)$ and guilty individuals are better off under mandatory disclosure if $y>\left(p_{g}-r_{g}\right) /\left(1-r_{g}\right)$.

Proof. We compare directly the expected probabilities of conviction under mandatory (passive) and under voluntary disclosure (active):

$$
\begin{aligned}
& p_{\mathrm{i}}>x+(1-x) r_{\mathrm{i}}, \\
& p_{\mathrm{g}}<y+(1-y) r_{\mathrm{g}} .
\end{aligned}
$$

Direct computation yields the two expressions mentioned in the proposition.

Let us explain why these conditions are likely to be verified. They impose that incriminating evidence is not very likely to be found for innocent defendants, whereas it is likely to be found for guilty defendants. Although the conditions do not follow from previous assumptions, we suggest they are likely to be satisfied. Proposition 3 also relies on the ability of the prosecutor to hide some exculpatory evidence but not all under voluntary disclosure. If the prosecutor is able to perfectly eliminate all exculpatory evidence, by construction, $r_{\mathrm{i}}=p_{\mathrm{i}}$ and $p_{\mathrm{g}}=r_{\mathrm{g}}$. Under this assumption, innocents are always better off under mandatory disclosure since otherwise exculpatory evidence can never be known. Consider now the opposite example. Exculpatory evidence always becomes known if it is obtained by the prosecutor despite her effort to hide it. In this scenario, $r_{\mathrm{i}}=r_{\mathrm{g}}=0$. Mandatory and voluntary disclosures of evidence are formally equivalent. Therefore, unsurprisingly, $C b=C c$.

Table 3 summarizes the results.

Remark. Under mandatory disclosure (as compared to a voluntary disclosure), (i) the guilty are better off on average; (ii) some innocents are better Table 3. Comparison of Outcomes under Different Prosecutorial Strategies when Mandatory Disclosure is Introduced Conditional on Type

\begin{tabular}{lcc}
\hline & \multicolumn{3}{c}{ Voluntary to mandatory } \\
\cline { 2 - 4 } & Guilty & Innocent \\
\hline Drop & $=$ & $=$ \\
Passive & $=$ & $=$ \\
Switch & + & - \\
Active & + & + \\
Average & + & $+/-$ \\
\hline
\end{tabular}


off (those for whom prosecutors are active); (iii) some innocents are worse off (those matched with prosecutors that change their behavior in response to mandatory disclosure); and (iv) if the number of cases for which prosecutors switch strategy in response to mandatory disclosure is overwhelming (more likely when prosecutors are selfish with $V=1$ and less likely when prosecutors dislike convicting innocents with $V=0$ ), the innocent is worse off on average.

When the distribution of enforcement costs is such that the number of defendants exposed to switch in Table 3 is minimal, mandatory disclosure is welfare maximizing as suggested by the standard literature. However, when the number of defendants exposed to switch is maximal, voluntary disclosure is more appropriate from the perspective of the welfare of innocent defendants.

\subsection{Risk-Averse Prosecutors}

Suppose now prosecutors are risk averse. We argue that nothing changes substantially in the model:

$$
\left\{\begin{array}{l}
U_{\mathrm{MD}, \mathrm{VD}}^{\mathrm{drop}}=U(0), \\
U_{\mathrm{MD}, \mathrm{VD}}^{\mathrm{passive}}=q U\left[p_{\mathrm{g}}-S(C)\right]+(1-q) U\left[p_{\mathrm{i}} V-S(C)\right], \\
U_{\mathrm{MD}}^{\mathrm{active}}=q U[y-C-S(C)]+(1-q) U[x V-C-S(C)], \\
U_{\mathrm{VD}}^{\mathrm{active}}=q U\left[y+(1-y) r_{\mathrm{g}}-C-S(C)\right] \\
+(1-q) U\left[\left(x+(1-x) r_{\mathrm{i}}\right) V-C-S(C)\right] .
\end{array}\right.
$$

The equations describe standard von Neumann-Morgenstern utility functions for the prosecutor under the different actions. We should start by observing that only the strategy drop described in Equation (3) (prosecutor's utility function in cases of $d r o p$ for both mandatory disclosure and voluntary disclosure) is risk free. Equation (4) describes prosecutor's utility when passive. The implicit definition of $\mathrm{Ca}$ goes down because of the concavity of the function. A similar reasoning can be made for $C b$ and $C c$ observing Equations (5) and (6). So a risk-averse prosecutor, all the rest being equal, would be less likely to be passive and even less likely to be active. Mathematically, we expect $C a, C b$, and $C c$ to all go down. More cases will be dropped, and fewer cases will be prosecuted under an active strategy under both rules. However, from our perspective, the relevant cases are the ones between $C b$ and $C c$. The immediate observation is that these cases are likely to exist unless risk 
aversion is so significant that the active strategy is never chosen. As to the proportion of cases, we know both interval limits go down, the question being which goes down further. In order to answer this question, we should observe that the active strategy is riskier under mandatory than under voluntary disclosure because, in the case of exculpatory evidence, the probability of conviction is lowest in the former, all the rest being constant. Intuitively, we expect $C b$ to decrease more than $C c$. With risk aversion, the interval of cases exposed to switching of strategies is likely to widen. Therefore, the introduction of risk aversion reinforces rather than limits our main claim.

\section{Legal Policy Implications}

Our model explains why the Brady rule may have a very different impact on the welfare of the accused. Depending on which effects identified by the model prevail, pro-defendant criminal procedure might benefit the guilty and hurt the innocent. This has consequences not only for the quality of criminal procedure as we have discussed in the model (false positives and false negatives) but also for deterrence. From previous literature, ${ }^{23}$ we know that if a certain rule or policy hurts the innocent and benefits the guilty (or more generally, if a rule benefits the guilty more than the innocent), then it fosters criminal activities. The reason is that the relative cost of violating the law is reduced. Conversely, pro-defendant criminal procedure that helps the innocent and hurts the guilty (more generally, any rule that hurts the guilty more than the innocent) increases deterrence. In terms of deterrence, the model suggests that mandatory disclosure induces undercompliance (because it is likely that the guilty benefits more than the innocent due to the change of behavior on the prosecutor's side) under certain conditions. Naturally, our model is based on a set of assumptions that are disputable, and therefore they will be discussed in the next paragraphs.

\subsection{Behavior of Jury and Judge}

One possible objection to our results concerns their robustness to the introduction of a jury or a judge that can make inferences from the evidence

23. See Png (1986) and Polinsky and Shavell (2000) for models in which false positives jeopardize deterrence. See further discussion in Lando (2006) and Garoupa and Rizzolli (2010). 
that the prosecutor presents in court when the prosecutor can withhold evidence (i.e., when there is no Brady rule in place).

There are two possible situations. When both the defendant and the court are unaware of the possibility of existence of more evidence than the one presented by the prosecution (e.g., the hidden cameras in our second example), there is no unraveling in terms of the jury and the judge making inferences. However, when the court suspects that some additional evidence might exist but the prosecutor has decided not to pursue it, the jury and the judge are likely to draw some inference.

Without mandatory disclosure, the jury is aware that the prosecutor might be silent about evidence favorable for the defendant, and they will factor this in when inferring the guilt or innocence of the defendant. The nature of the inference the jury or the judge makes, when a prosecutor can withhold exculpatory evidence, depends on the costs of false positives and false negatives (Schrag and Scotchmer, 1994) and the updating mechanism (Froeb and Kobayashi, 1996). If we operate in the framework of pure Bayesian update, it has been shown that the exclusionary rule reduces the actual standard of proof because the jury takes into account that relevant incriminatory evidence might have not been presented in court (Edman, 2001). Quite straightforwardly, when there is the possibility that exculpatory evidence has been withheld by the prosecutor, a Bayesian jury should increase the standard of proof.

In terms of our model, the existence of a Bayesian jury or judge that adjusts to the possibility of prosecutors withholding exculpatory evidence implies a reduction in the probabilities of conviction when the prosecutor is active. Necessarily, for the prosecutor the expected payoff of being active is decreased when exculpatory evidence can be withheld. However, we think our result is robust to this framework. If, when a prosecutor is active, her expected payoff is higher when disclosing exculpatory evidence than when withholding it (due to the inference of the jury or of the judge), then she will disclose such evidence voluntarily. Hence, at most, mandatory disclosure has no practical effect because the prosecutor discloses information voluntarily. Clearly this possibility seems quite unrealistic. Therefore, it is likely to be the case that the expected payoff of the prosecutor is still higher when evidence is not disclosed, hence making our simple framework robust to Bayesian updates.

Our reasoning so far is based on the assumption that the court can distinguish an active from a passive prosecutor, which seems reasonable. Moreover, it will be easy for a passive prosecutor to signal her strategy and hence 
avoid the reduction in expected payoff that a pooling equilibrium would carry for her (as noted above, a Bayesian jury observing an active strategy may impose an higher standard of proof and consequently increase the costs of prosecution). She only has to show that she has not invested resources in fact discovery. Obviously, if the jury cannot distinguish active from passive, there is less information available to support Bayesian inference, and our model is more likely to describe the essence of what is going on.

Summing-up, our simple model captures the essential strategic effect that resists more complex specifications. The expected payoff of the prosecutor is higher when there is no mandatory disclosure of evidence. Hence, when exculpatory evidence has to be revealed, some prosecutors will prefer to be passive, which in turn hurts the innocent.

\subsection{Standard of Proof}

It is likely that a rule of mandatory disclosure interacts with the specific standard of proof for reasons that could be different from the existence of a Bayesian jury or judge. If the standard of proof is significantly high, the prosecutor faces an additional incentive to search for more evidence. If so, the chilling effect generated by mandatory disclosure is marginal since the effective constraint faced by the prosecutor is to satisfy the beyond reasonable doubt standard. In this context, a rule of mandatory disclosure of evidence cannot hurt innocent defendants. However, if the standard of proof is satisfied by the prosecutor with some particular evidence, the chilling effect generated by mandatory disclosure is important since she needs no further search to secure a conviction.

\subsection{Behavior of the Prosecutor: Ethics and Codes of Conduct}

Our model allows for the possibility of a remorseless prosecutor as well as for the possibility of a prosecutor who dislikes obtaining convictions of innocents (but she cannot avoid this since there is asymmetric information and culpability cannot be perfectly identified). When prosecutors are merely opportunistic and do not care about the degree of culpability of defendants, the parameter $V$ goes up, and the number of defendants exposed to detrimental switching of prosecutorial strategy is higher. Notice, however, that even when prosecutors dislike convicting the innocent, the effect we have identified exists; it just happens that the number of defendants exposed to such effect is lower but never zero. 
From the perspective of innocent defendants, it is important to reduce prosecutorial opportunism, so as to moderate the detrimental switching of prosecutorial strategy. Naturally, rules of ethics for prosecutors play a significant role in this context.

\subsection{Behavior of the Prosecutor: Compliance with Mandatory Disclosure}

The model presupposes that prosecutors comply with the Brady rule whenever it applies. The reality is that prosecutors can still manage what evidence is exculpatory and has to be disclosed and what evidence is irrelevant or unrelated to the charges and should not be disclosed. The decision is likely to be more relevant for the innocent defendants than for the guilty. The reason is that the evidence the prosecutor does not want to disclose is probably favorable to the defendant. Therefore, we should reinterpret the probability of conviction of an innocent to be zero when the favorable evidence is disclosed as a mere normalization. Once we recognize that compliance with mandatory disclosure is not assured because prosecutors are opportunistic, there are questions concerning enforcement mechanisms and sanctioning. To the extent that mandatory disclosure is to be effective, compliance should be achieved at the lowest cost. Naturally, these costs have to be balanced against the benefits of assuring effective mandatory disclosure.

\subsection{Behavior of the Prosecutor: Evidence and Discovery}

The recognition that prosecutors could engage in opportunistic behavior raises important questions concerning evidence and discovery. As our focus is on mandatory disclosure, in our model prosecutors can only hide evidence (but they cannot fabricate it, e.g.). The extent to which evidence and discovery rules can reduce the gains to the prosecutor from engaging in opportunistic conduct is relevant; the less transparent evidence rules are, the more significant is the problem we raise. Pro-defendant criminal procedure rules might have unintended consequences because prosecutors adjust their strategies.

Furthermore, the incentives for the prosecutor to invest less in the search process derived from the Brady rule could have a serious impact in the shaping of the available technology for criminal investigation in the long run. Better or more advanced search technologies could not be discovered due to lack of interest by the prosecution. 
An important positive effect of the Brady rule that should not be neglected in the analysis is that by not improving the accuracy of criminal investigation, it reduces the incentives for predation in the prosecutor's office. The defendant can no longer rely on the prosecutor looking for the information because he should anticipate the prosecutor's preference for a less careful search. The consequences of this effect depend crucially on the behavior of the accused.

A related beneficial effect of the Brady rule is providing incentives to the prosecutor to waste fewer resources. Eliminating exculpatory evidence is socially wasteful for two reasons. First, it provides information about the defendant. Second, it is costly to be produced. If the prosecutor is free to discard evidence when it turns out to be exculpatory, she could engage in a socially excessive search or production of evidence. By forcing revelation of evidence, a mandatory disclosure rule reduces the social costs of evidence production.

\subsection{Behavior of the Accused}

In the model, from a pure game theoretical viewpoint, the defendant is passive. In our view, the assumption is fairly realistic and can be justified in three different ways. The most immediate explanation is that on many occasions the defendant does not know about the existence of such potentially exculpatory evidence (only the prosecution has such information). The second explanation relates to the fact that a high percentage of defendants are represented by pro bono counselors or public defenders who usually are not eager to engage in expensive and aggressive defensive strategies (Rhee, 1996; Seron et al., 2001; Sandefur, 2007). Similarly, we could have situations where the defendant's counselor is incompetent or inept. Finally, it could be that the defendant is aware of the existence of potentially exculpatory evidence and his lawyer is competent, but the costs of discovery are simply too high.

Consider the examples we discussed in the introduction. In our first example, it could be that the defendant and the court do not know about the existence of hidden cameras close to the scene of the crime. In the second and third examples, we could have inept lawyers representing the defendant or he might be unaware of the existence of complex international financial statements (second example) or confidential documents filed with the government (last example). 
In fact, our model essentially captures the idea of a defendant who relies heavily on the evidence produced by the public authority and is therefore not playing an active role in criminal litigation. The model is of a game between the prosecutor and nature. Introducing the possibility for different strategies for the accused makes the model more complex and more realistic. Plausibly, a defendant can also choose between being passive or active (trying to produce evidence to support her innocence). Depending on how the behavior of each side determines the probability of a conviction for the guilty and for the innocent, different game structures are possible. We could have a correlated equilibrium (both sides are passive or both sides are active). We could also have a game with no equilibrium in pure strategies. Although modeling the behavior of the accused introduces more complexity, the identified effects of mandatory disclosure for the prosecutor still exist.

Mandatory disclosure for the prosecutor, as we have seen, could make the prosecutor more passive and therefore hurt the innocent. The reaction of the defendant could mitigate the problem (for instance, just suppose the accused becomes more active in gathering evidence). But this would naturally increase the legal costs for an innocent defendant who has to search and discover evidence to support her innocence rather than waiting for the prosecutor to do that.

In conclusion, a more complex model that explicitly accounts for the behavior of the defendant does not eliminate the problems we have identified with mandatory disclosure. It is possible that the accused could counterbalance the change of the prosecutor's behavior and therefore mitigate the dilemmas we have discussed in the model. However, such mitigation is costly and therefore would increase the burden borne by an innocent defendant.

\section{Conclusions}

In this paper, we have studied the effects of mandatory disclosure of exculpatory evidence, the so-called Brady rule, on the behavior of prosecutors. We have shown that mandatory disclosure of evidence may make the prosecutor act passively since she loses any informative advantage and this may end up hurting innocent defendants. In fact, the change of behavior by the prosecutor affects the welfare of the defendant; however, this effect is not the same on all types of defendants and it crucially depends on whether the defendant is guilty or innocent. We have argued that, under certain 
circumstances, these rules hurt the innocent and benefit the guilty. Such observation carries two important implications. By inducing changes in the prosecutor's behavior, mandatory disclosure could actually decrease the quality of criminal convictions (by increasing false positives) and reduce criminal deterrence (by increasing the net returns from crime).

We have identified the strategic role of the prosecutor as a major determinant of the efficacy of pro-defendant criminal procedure rules. While previous literature has argued that full discretion on the side of the prosecutor promotes efficiency, we take the view that it could seriously undermine the quality of criminal justice and deterrence. The critical question is the extent to which the goals of the prosecutor are misaligned with those of society in general. If they are, then pro-defendant criminal procedure rules such as mandatory disclosure could exacerbate the problem.

The extent to which the detrimental effect of the Brady rule on the welfare of innocent defendants matters is inevitably an empirical question. Under the conditions we have derived in the paper, if prosecutors hardly adjust their behavior and are active most of the time, then mandatory disclosure is welfare maximizing. However, if switching behavior is a frequent reaction of prosecutors to disclosure rules, our article suggests that we should be careful in assessing the merits of the Brady rule. Under very specific circumstances, voluntary disclosure is better. When designing disclosure rules, the possibility of such specific circumstances emerging should not be neglected.

\section{References}

Albonetti, Celesta A. 1987. "Prosecutorial Discretion: The Effects of Uncertainty," 21 Law and Society Review 291-314.

American Bar Association. 1993. ABA Standards for Criminal Justice. Prosecution Function and Defense Function. Washington, DC: American Bar Association.

Atkins, Raymond A., and Paul H. Rubin. 2003. "Effects of Criminal Procedure on Crime Rates: Mapping Out the Consequences of the Exclusionary Rule," 46 Journal of Law and Economics 157-79.

Baker, Scott, and Mezzetti, Claudio. 2001. "Prosecutorial Resources, Plea Bargaining, and the Decision to Go to Trial," 17 Journal of Law Economics and Organization 149-67.

Becker, Gary. 1968. "Crime and Punishment: An Economic Approach,” 76 Journal of Political Economy 169-217. 
Bedau, Hugo A., and Michael L. Radelet. 1987. "Miscarriages of Justice in Potentially Capital Cases," 40 Stanford Law Review 21-179.

Boylan, Richard T. 2005. "What Do Prosecutors Maximize? Evidence from the Careers of US Attorneys," 7 American Law and Economics Review 379.

Cassell, Paul G., and Richard Fowles. 1998. "Handcuffing the Cops? A Thirty-Year Perspective on Miranda's Harmful Effects on Law Enforcement," 50 Stanford Law Review 1055-145.

Christensen, Dirk G. 1981. "Incentives vs. Nonpartisanship: The Prosecutorial Dilemma in an Adversary System," 2 Duke Law Journal 311-7.

Cooter, Robert D., and Winand Emons. 2003. "Truth-Revealing Mechanisms for Courts," 159 Journal of Institutional and Theoretical Economics 259-79.

- 2004. "Truth-Bonding and Other Truth-Revealing Mechanisms for Courts," 17 European Journal of Law and Economics 307-27.

Cooter, Robert D., and Daniel L. Rubinfeld. 1994. "An Economic Model of Legal Discovery," 23 Journal of Legal Studies 435-63.

Demougin, Dominique, and Claude Fluet. 2006. "Preponderance of Evidence," 50 European Economic Review 963-76.

Easterbrook, Frank H. 1983. "Criminal Procedure as a Market System," 12 Journal of Legal Studies 289-332.

Edman, Carl. 2001. "Rational Jurors and Extrinsic Exclusionary Rules," John M. Olin Fellowship in Law and Economics, Georgetown University Law Center.

Fletcher, George P. 1995. With Justice for Some: Victims' Rights in Criminal Trials. Reading, MA: Addison-Wesley.

Froeb, Luke M., and Bruce H. Kobayashi. 1996. "Naive, Biased, Yet Bayesian: Can Juries Interpret Selectively Produced Evidence?” 12 Journal of Law, Economics, and Organization 257-76.

Garoupa, Nuno. 1997. "The Theory of Optimal Law Enforcement," 11 Journal of Economic Surveys 267-95.

_. 2009. "Some Reflections on the Economics of Prosecutors: Mandatory vs. Selective Prosecution," 29 International Review of Law and Economics 25-8.

Garoupa, Nuno, and Matteo Rizzolli. 2010. "Wrongful Convictions Do Lower Deterrence." University of Illinois \& Free University of Bozen-Bolzano Mimeograph.

Garoupa, Nuno, and Frank Stephen. 2008. "Why Plea-bargaining Fails to Achieve Results in so Many Criminal Justice Systems: A New Framework for Assessment," 15 Maastricht Journal of European and Comparative Law 319-54.

Gelman, Andrew, James S. Liebman, Valerie West, and Alexander Kiss. 2004. "A Broken System: The Persistent Patterns of Reversals of Death Sentences in the United States," 1 Journal of Empirical Legal Studies 209-61.

Gershman, Bennett L. 2006. "Reflections on Brady v. Maryland," 47 South Texas Law Review 685-949. 
Glaeser, Edward L., Daniel P. Kessler, and Anne Morrison Piehl. 2000. "What do Prosecutors Maximize? An Analysis of the Federalization of Drug Crimes," 2 American Law and Economics Review 259-90.

Gordon, Sanford C., and Gregory A. Huber. 2002. "Information, Evaluation, and the Electoral Incentives of Criminal Prosecutors," 46 American Journal of Political Science 334-51.

Green, Bruce A. 2003. "Prosecutorial Ethics As Usual," University of Illinois Law Review 1573-603.

Hay, Bruce L., and Kathryn E. Spier. 1997. "Burdens of Proof in Civil Litigation: An Economic Perspective," 26 Journal of Legal Studies 413-31.

Hylton, Keith N. 2005. "The Theory of Penalties and the Economics of Criminal Law," 1 Review of Law and Economics 175-201.

Hylton, Keith N., and Vikramaditya S. Khanna. 2007. "A Public Choice Theory of Criminal Procedure," 15 Supreme Court Economic Review 61-118.

Ingraham, Barton L. 1996. "The Right of Silence, the Presumption of Innocence, the Burden of Proof, and a Modest Proposal: A Reply to O'Reilly," 86 Journal of Criminal Law and Criminology 559-95.

Jackson, Robert H. 1940. "The Federal Prosecutor," 24 Journal of the American Judicature Society 18-9.

Kahan, Dan M. 1998. "Social Meaning and the Economic Analysis of Crime," 27 Journal of Legal Studies 609-22.

Kaplow, Louis. 1994. "The Value of Accuracy in Adjudication: An Economic Analysis," 23 Journal of Legal Studies 307-401.

Kurcias, Lisa M. 2000. "Prosecutor's Duty to Disclose Exculpatory Evidence," 69 Fordham Law Review 1205-29.

Landes, William M. 1971. "An Economic Analysis of the Courts," 14 Journal of Law and Economics 61-107.

Lando, Henrik. 2006. "Does Wrongful Conviction Lower Deterrence?” 35 Journal of Legal Studies 327-38.

Long, Cheryl X., and Richard T. Boylan. 2005. "Salaries, Plea Rates, and the Career Objectives of Federal Prosecutors," 48 Journal of Law and Economics 627-709.

Mahoney, Paul G. 1995. "Mandatory Disclosure as a Solution to Agency Problems," 62 University of Chicago Law Review 1047-112.

Meares, Tracey L. 1995. "Rewards for Good Behavior: Influencing Prosecutorial Discretion and Conduct with Financial Incentives," 64 Fordham Law Review 851-919.

Mialon, Hugo M. 2005. “An Economic Theory of the Fifth Amendment," 36 RAND Journal of Economics 833-48.

Miceli, Thomas J. 1990. "Optimal Prosecution of Defendants Whose Guilt Is Uncertain," 6 Journal of Law, Economics, and Organization 189-201.

1991. "Optimal Criminal Procedure: Fairness and Deterrence," 11 International Review of Law and Economics 3-10. 
Milgrom, Paul, and John Roberts. 1986. "Relying on the Information of Interested Parties," 17 RAND Journal of Economics 18-32.

O'Reilly, Gregory W. 1994. "England Limits the Right to Silence and Moves Towards an Inquisitorial System of Justice," 85 Journal of Criminal Law and Criminology 402-52.

Png, Ivan P. L. 1986. "Optimal Subsidies and Damages in the Presence of Judicial Error," 6 International Review of Law and Economics 101-5.

Polinsky, A. Mitchell, and Steven Shavell. 2000. "The Economic Theory of Public Enforcement of Law," 38 Journal of Economic Literature 45-76.

- 2006. Mandatory Versus Voluntary Disclosure of Product Risks. NBER Working Paper W12776.

Posner, Richard A. 1985. "An Economic Theory of the Criminal Law," 85 Columbia Law Review 1193-231.

Rasmusen, Eric, Manu Raghav, and J. Mark Ramseyer. 2009. “Convictions versus Conviction Rates: The Prosecutor's Choice," 11 American Law and Economics Review 47-78.

Rhee, Christopher S. 1996. "Pro Bono, Pro Se," 105 Yale Law Journal 1719-24.

Rubinfeld, Daniel L., and David E. M Sappington. 1987. "Efficient Awards and Standards of Proof in Judicial Proceedings," 18 RAND Journal of Economics 308-15.

Sanchirico, Chistian W. 1997. "The Burden of Proof in Civil Litigation: A Simple Model of Mechanism Design," 17 International Review of Law and Economics 431-47.

Sandefur, Rebecca L. 2007. "Lawyers' Pro Bono Service and American-Style Civil Legal Assistance," 41 Law and Society Review 79-112.

Schrag, Joel, and Suzanne Scotchmer. 1994. "Crime and Prejudice: The Use of Character Evidence in Criminal Trials," 10 Journal of Law, Economics, and Organization 319-42.

Schulhofer, Stephen J. 1988. "Criminal Justice Discretion as a Regulatory System," 17 Journal of Legal Studies 43-82.

Seidmann, Daniel J. 2005. "The Effects of a Right to Silence," 72 Review of Economic Studies 593-614.

Seidmann, Daniel J., and Alex Stein. 2000. "The Right to Silence Helps the Innocent: A Game-Theoretic Analysis of the Fifth Amendment Privilege," 114 Harvard Law Review 430-510.

Seron, Carroll, Martin Frankel, Van Ryzin Greg, and Jean Kovath. 2001. "The Impact of Legal Counsel on Outcomes for Poor Tenants in New York City's Housing Court: Results of a Randomized Experiment," 35 Law and Society Review 419-34.

Shavell, Steven. 1989. "Optimal Sanctions and the Incentive to Provide Evidence to Legal Tribunals," 9 International Review of Law and Economics 3-11. . 1994. "Acquisition and Disclosure of Information Prior to Sale," 25 RAND Journal of Economics 20-36. 
200 American Law and Economics Review V13 N1 2011 (168-200)

Shin, Hyun S. 1998. "Adversarial and Inquisitorial Procedures in Arbitration," 29 RAND Journal of Economics 378-405.

Wright, Ronald F. 2005. "Trial Distortion and the End of Innocence in Federal Criminal Justice," 154 University of Pennsylvania Law Review 79-156.

Yilankaya, Okan. 2002. "A Model of Evidence Production and Optimal Standard of Proof and Penalty in Criminal Trials," 35 Canadian Journal of Economics 385-409. 